\title{
Search for mycoplasma in synovial fluids from patients with rheumatoid arthritis
}

\author{
G. D. WINDSOR, (1) A. NICHOLLS, ${ }^{(2)}$ R. N. MAINI, (2) D. G. FF. EDWARD, ${ }^{(3) *}$ \\ R. M. LEMCKE, (4) AND D. C. DUMONDE ${ }^{(2)}$ \\ From the Wellcome Research Laboratories, ${ }^{(1)}$ Beckenham, Kent, the Kennedy Institute of Rheumatology, ${ }^{(2)}$ \\ London, the Public Health Laboratory, ${ }^{(3)}$ County Hall, London, and the Lister Institute of \\ Preventive Medicine, London ${ }^{(4)}$
}

The isolation of Mycoplasma fermentans from over 40 per cent. of synovial fluids taken from patients with rheumatoid arthritis has been reported by Williams (1967a, b; 1970). Although other studies have suggested an association between this disease and other species of mycoplasma (Bartholomew, 1965; Jansson and Wager, 1967; Jansson, Mäkisara, Vainio, Vainio, Snellman, and Tuuri, 1971; Fraser, Shirodaria, Haire, and Middleton, 1971), the possibility that $M$. fermentans was associated with rheumatoid arthritis was supported by the finding that there was inhibition of peripheral leucocyte migration in the presence of extracts of $M$. fermentans, indicating the existence of a specific immunological response (Williams, Brostoff, and Roitt, 1970). In view of the importance of such an association between $M$. fermentans and rheumatoid arthritis, we have attempted to isolate mycoplasmas from synovial fluids by techniques including those described by Williams.

\section{Methods}

Source of synovial fluids

Synovial fluids were obtained from knee effusions by needle aspiration under aseptic conditions from 43 patients with rheumatoid arthritis and five non-rheumatoid patients (Table I). The patients with rheumatoid disease were categorized according to the American Rheumatism Association criteria (1959) as follows: 'Classical' 28; 'Definite' 10; 'Probable' 5. All patients had active polyarthritis and the duration of disease in ten was less than 1 year; in twelve between 1 and 5 years; and in 21 greater than 5 years. At the time of the aspiration no patients were receiving antibiotics and none had been treated with gold or chloroquine in the preceding 12 weeks. Altogether 68 synovial fluids were obtained from 43 rheumatoid patients, in many instances by aspiration of both knees during the same session, and in a few on a second aspiration following reaccumulation of fluid. Synovial fluids from knee joints were also obtained from five non-rheumatoid patients whose diagnosis is detailed in Table $\mathbf{I}$.

The fluids were placed in sterile bijou bottles and
Table I Rheumatoid arthritis patients (total 43)

\begin{tabular}{|c|c|}
\hline (1) Disease classification (A.R.A.)*: & $\begin{array}{l}\text { Classical } \\
\text { Definite } \\
\text { Probable }\end{array}$ \\
\hline (2) Duration of disease (yrs): & $\begin{array}{l}\text { Less than } 1 \\
1-5 \\
>5\end{array}$ \\
\hline
\end{tabular}

(3) Total number of synovial fluids 68

Non-rheumatoid patients (total 5)

\begin{tabular}{ll}
\hline Osteoarthritis & 3 \\
Reiter's syndrome & 1 \\
Acromegaly & 1
\end{tabular}

* American Rheumatism Association criteria (see reference).

transported at ambient temperature for direct inoculation into a variety of media (Table II) and for Series I of the density gradient separations (Table III). For Series II and III of the gradient separations, the aspirates were transported on ice. The duration between aspiration and setting

Table II Direct inoculation and culture of synovial fluids in mycoplasma media: cultural procedures employed in two independent laboratories

\begin{tabular}{|c|c|c|c|}
\hline \multirow[b]{2}{*}{ Inoculation* } & \multicolumn{3}{|c|}{ Synovial fluids (neat and 1/10 dilution) } \\
\hline & $\begin{array}{l}\text { Agar plates } \\
\text { (AER and } \\
\text { AN) } \dagger\end{array}$ & $\begin{array}{c}\text { Semi-solid } \\
\text { medium }\end{array}$ & T-broth \\
\hline $\begin{array}{l}\text { Observation } \\
\text { period (days) }\end{array}$ & $14-28$ & $14-28$ & 14 \\
\hline Subcultures & - & $\begin{array}{l}\text { Broth to plates } \\
\text { (AN) on 7th } \\
\text { and 14th day }\end{array}$ & 一 \\
\hline
\end{tabular}

Results

Eleven rheumatoid and three non-
rheumatoid fluids examined:
No mycoplasmas isolated

* Details of media in text.

$\dagger \mathrm{AER}=$ Aerobic culture; $\mathrm{AN}=$ Anaerobic $\left(95\right.$ per cent. $\mathrm{N}_{2} / 5$ per cent . $\mathrm{Co}_{2}$ ) culture. 
Table III Culture of synovial fluids separated on sucrose gradients: (details of procedure)

\begin{tabular}{|c|c|c|c|c|}
\hline Series & & $I$ & II & III \\
\hline Transport (temperature) & & Bijou (ambient) & Bijou (ice) & Bijou in sachet (ice) \\
\hline Inoculation of visible bands & (a) & $\begin{array}{l}\text { Plate (AN) } \\
\text { Semisolid }(0.1 \mathrm{ml} .)^{*}\end{array}$ & $\begin{array}{l}\text { Plate (AN) } \\
\text { Broth }(0 \cdot 2 \mathrm{ml} .)\end{array}$ & $\begin{array}{l}\text { Plates (AER and AN) } \dagger \\
\text { Broth }(0.2 \mathrm{ml} .)\end{array}$ \\
\hline Subcultures & & $\begin{array}{l}\text { Semisolid culture onto } \\
\text { Plates (AN) on } \\
\text { Day } 4,7, \text { and } 14\end{array}$ & $\begin{array}{l}\text { Original broth culture } \\
\text { Plates (AN) } \\
\text { Day 7, 14, and } 21\end{array}$ & broth and onto \\
\hline
\end{tabular}

* Volume of gradient inoculated into liquid medium.

$\uparrow \mathrm{AER}=$ Aerobic culture; $\mathrm{AN}=$ Anaerobic $\left(95 \% \mathrm{~N} 2 / 5 \% \mathrm{Co}_{2}\right)$ culture.

up of density gradients or direct inoculation into media was 2 to $4 \mathrm{hrs}$, except for 22 out of 33 synovial fluids in Series I (Table IV) which were stored at $-70^{\circ} \mathrm{C}$. before density gradient separation and subsequent culture.

Table IV Cultural results on synovial fluids separated on sucrose gradients

\begin{tabular}{|c|c|c|c|c|}
\hline Series & $\bar{I}$ & $I I$ & $I I I$ & Total \\
\hline $\begin{array}{l}\text { No. of fluids from } \\
\text { (a) Rheumatoid patients } \\
\text { (b) Non-rheumatoid } \\
\text { patients }\end{array}$ & $\begin{array}{r}29 \\
4\end{array}$ & $\begin{array}{r}17 \\
1\end{array}$ & $\begin{array}{r}18 \\
0\end{array}$ & $\begin{array}{r}64 \\
5\end{array}$ \\
\hline No. of bands cultured & 65 & 41 & 43 & 149 \\
\hline Acid colour changes & 3 & 15 & 4 & 22 \\
\hline $\begin{array}{l}\text { Evidence of bacterial } \\
\text { contamination* }\end{array}$ & 1 & 16 & 4 & 21 \\
\hline Mycoplasma isolations & 0 & $\mathbf{0}$ & $\mathbf{0}$ & $\mathbf{0}$ \\
\hline
\end{tabular}

Series I, II, and III refer to classification in Table III.

* See text.

\section{Media}

The composition of the media was basically that described by Chanock, Hayflick, and Barile (1962). For liquid and semi-solid media (the latter containing 0.07 per cent. Oxoid Ionagar No. 2), the serum supplement was horse serum ( 20 per cent., $v / v)$. Glucose $(0 \cdot 1$ per cent, w/v) and phenol red $(0.002$ per cent., w/v) were included, as well as penicillin $(200$ units $/ \mathrm{ml}$.) and thallous acetate $(1 / 4,000)$ as bacterial inhibitors. Three types of solid medium were used, one containing horse serum and inhibitors at the concentrations given above, a second containing horse serum but no inhibitors, and a third with pig serum ( 20 per cent., $\mathrm{v} / \mathrm{v}$ ) and inhibitors. In addition, T-broth, a medium for T-strain mycoplasmas based on the formula of Csonka, Williams, and Corse (1966), with added urea (0.1 per cent., w/v) and phenol red was used. Horse sera, yeast extract, and agar constituents were pre-tested for their ability to support growth by counting colonyforming units in cultures of $M$. pneumoniae, $M$. gallisepticum, and $M$. synoviae. Other constituents were tested in liquid and solid media by passage of $M$. fermentans (PG18) and seven other stock strains.

The composition of the sucrose density gradients was similar to that described by Williams (1970) and comprised-1 $\mathrm{ml}$. 90 per cent., $0 \cdot 5-\mathrm{ml}$. amounts of $85,80,75$, and 70 per cent., and $1 \mathrm{ml} .50$ per cent. sucrose. After equilibration overnight at $4^{\circ} \mathrm{C}$., $1 \mathrm{ml}$. synovial fluid was layered onto the gradient and centrifuged for $2 \mathrm{hrs}$ at 20,000 r.p.m. in a Spinco SW39 rotor. The centrifuge tube containing the separated synovial fluid was placed over a light source and each visible band (usually two or more per specimen) was removed separately, from the top downwards, in approximately $0 \cdot 2-\mathrm{ml}$. amounts drawn up into a 1-ml. syringe through a blunt needle with the tip bent at an angle of $90^{\circ}$ (Williams, personal communication).

\section{Results}

(i) Direct inoculation of synovial fluids into culture media

Fourteen synovial fluids (11 rheumatoid and 3 non-? rheumatoid) were each divided into two, and one each was cultured in the laboratories at Beckenham and at County Hall, London, by direct inoculation into solid and liquid mycoplasma media (Table II). Each synovial fluid was plated onto three different agar media, into semi-solid medium, and T-broth. In both laboratories, semi-solid cultures were further sub-cultured onto agar plates after 7 and 14 days' incubation and in one laboratory additional subcultures into semisolid medium were also performed. No mycoplasmas were isolated.

(ii) Culture of synovial fluids after density gradient centrifugation

The 69 synovial fluids cultured after separation on density gradients can be separated into three series (Tables III and IV).

\section{SERIES I}

33 fluids were transported at ambient temperature and $0 \cdot 1-\mathrm{ml}$. amounts from each visible band were inoculated into solid and semisolid media. From these fluids a total of 65 bands were cultured (Table IV).

SERIES II

The fluids were transported on ice and the cultural methods were more closely aligned with those of Williams (personal communication) in that $0.2 \mathrm{ml}$. of each visible band was inoculated into $2 \mathrm{ml}$. broth 
contained in a 2-ml. vial. In contrast to Series I, there were acid colour changes in the majority of the inoculated broths (Table IV) and these were associated with the subsequent culture on mycoplasma agar of Achromobacter species. The colour changes were detected between 10 and 25 days after inoculation and were not associated with the turbidity usually encountered with bacterial contamination. The colour changes were not obtained in further passages.

\section{SERIES III}

To minimize possible sources of bacterial contamination, centrifuge tubes were gamma-irradiated and the bijou bottles containing the synovial fluids were transported in watertight sachets on ice. The cultural procedures were similar to those in Series II (Table III) but there was a marked reduction in the number of bacterial isolations from the bands cultured in Series III (Table IV). All four isolates from Series III were characterized as Flavobacterium aquatile.

No mycoplasmas were isolated from the synovial fluids in any of the three series. (iii) Deliberate inoculation and recovery of $\mathrm{M}$. fermentans from synovial fluids

To confirm that our techniques were capable of isolating $M$. fermentans, frozen broth cultures of the organism were placed on density gradients and centrifuged. The gradients were then sampled either by collecting fractions of the gradient allowed to drip through the punctured base of the centrifuge tube, or with a syringe by inserting a needle through the side wall of the tube containing the gradient at five different levels. Culture of these samples showed that colony-forming units of mycoplasma were distributed throughout the gradient but were most concentrated when taken from one of the visible bands (see Figure, band B). A total of six rheumatoid synovial fluids stored at $-70^{\circ} \mathrm{C}$. from which no $M$. fermentans had been previously isolated were deliberately inoculated with $M$. fermentans cultures; three were incubated for $1 \mathrm{hr}$ at $37^{\circ} \mathrm{C}$. and three were placed on ice for $2 \frac{1}{2} \mathrm{hrs}$ before layering on gradients. $M$. fermentans was recovered from the gradients after centrifugation in all six instances. The number of organisms was pre-determined in the three fluids

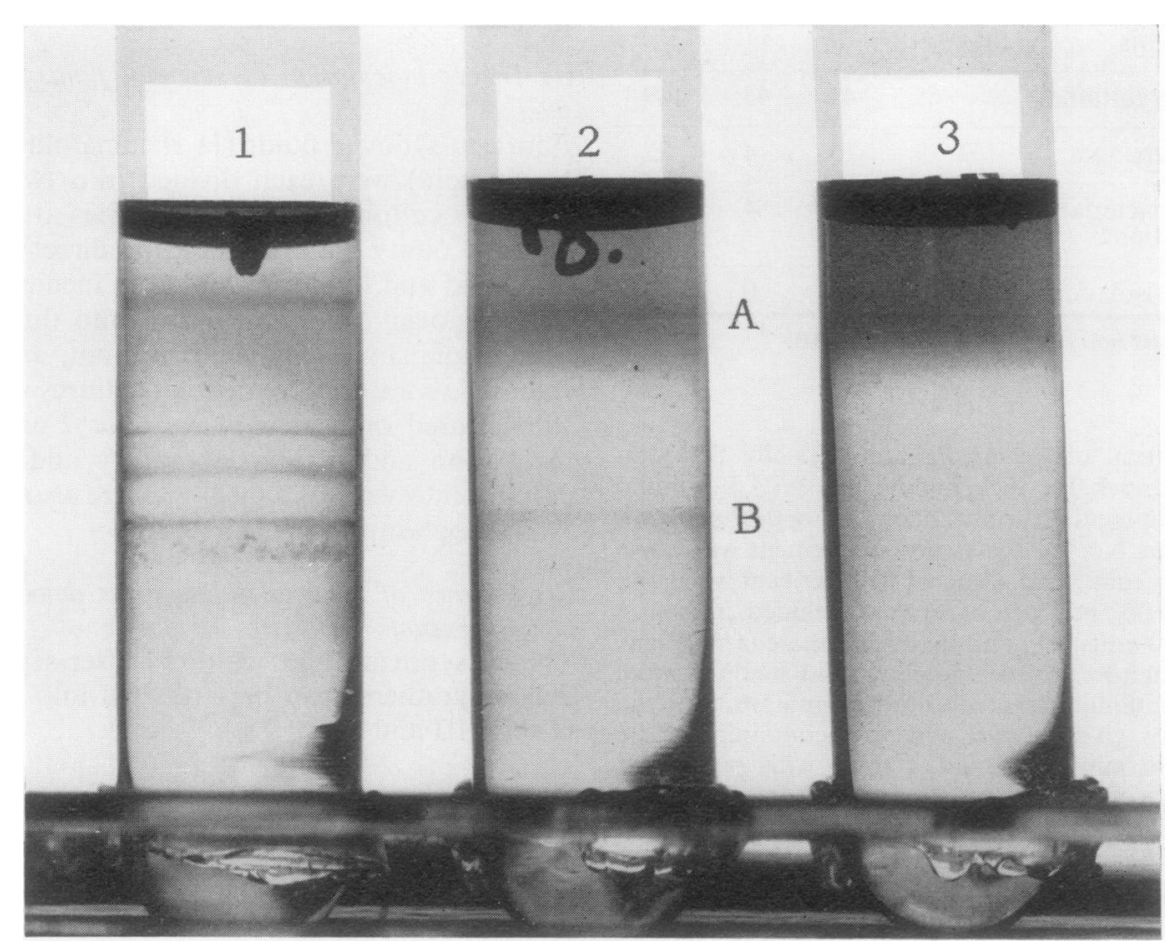

FIG UR E Photograph of sucrose density gradients after centrifugation at 20,000 r.p.m. for 2 hrs, each overlaid with 1 ml. of the following:

(1) Synovial fluid from a patient with rheumatoid arthritis

(2) Frozen and thawed broth culture of $M$. fermentans (line B is associated with a peak in the number of colony forming units; line $A$ is produced in uninoculated media by freezing and thawing)

(3) Uninoculated broth 
kept on ice, and it was estimated that $4 \times 10^{2}$ to $4 \times 10^{3}$ colony-forming units had been applied to the gradient.

\section{Discussion}

Reports on the recovery of mycoplasmas from human synovial fluids need to be interpreted with caution. When mycoplasmas have been isolated from synovial fluids or membranes inoculated into tissue cultures (Bartholomew, 1965; Fraser and others, 1971), or from primary cell cultures initiated from synovial membranes (Fraser and others, 1971), there are several possible sources of contamination, including commercial bovine serum (Barile and DelGiudice, 1972). Tissue cultures are notoriously prone to mycoplasma contamination (Stanbridge, 1971) and the incidence has been noted in some surveys to be as high as 70 to 80 per cent. (Sethi, 1972). M. hyorhinis was the organism most frequently isolated by Bartholomew (1967), and this mycoplasma (of porcine origin) is particularly regarded as a tissue culture contaminant (Sabin, 1967). It is noteworthy that some of the strains isolated by Fraser and others (1971) were also identified as $M$. hyorhinis by TaylorRobinson (1972) and another strain was identified by themselves as $M$. laidlawii, another known tissue culture contaminant (Barile and Kern, 1971). Jannson and Wager (1967) reported the isolation of $M$. arthritidis (a rat mycoplasma) from two patients with rheumatoid arthritis. The minute colonies obtained by Jannson and others (1971) from synovial fluids plated on media containing egg yolk have not yet been unequivocally shown to be mycoplasmas.

The isolation by Williams in artificial media of $M$. fermentans from 40 per cent. of rheumatoid synovial fluids prompted the present investigation. Nevertheless, using media pre-tested for their ability to support growth of mycoplasmas and the technique described by Williams, we have failed to confirm his findings. Visible bands were consistently seen when synovial fluids or broth cultures of $M$. fermentans (PG18) were centrifuged on sucrose density gradients (see Figure); but we doubt whether this indicates the presence of mycoplasmas in synovial fluid as suggested by Williams (1970). The particles found in rheumatoid synovial fluids by electron microscopy by Williams $(1967 \mathrm{a}, \mathrm{b})$ and regarded by him as minimal reproductive units of a mycoplasma, fall below the smallest size generally accepted for mycoplasmas (Maniloff, 1969; Lemcke, 1971). Our failure to isolate mycoplasmas seems all the more significant, since a stock strain of $M$. fermentans (PG18) was shown to be capable of surviving sucrose gradient centrifugation and could be consistently recovered from deliberately inoculated synovial fluids.

A fairly high incidence of water-borne species of Achromobacter and Flavobacterium was noted in this study. These organisms were especially prevalent when synovial fluids were transported on ice in Series II (Table III). When special precautions were taken to avoid contamination of the outside of the bijou bottles in Series III (Table III), the isolation of these organisms was markedly reduced, and it is therefore likely that the ice was the source of the bacteria. The acid colour changes observed in some broth media (Table IV) were associated with bacteria, but the colour change could not be passaged in broth and no mycoplasmas were detected on subculture on the usual mycoplasma agar plates. The colour changes were probably caused by bacteria although it is possible that synovial exudate cells were concentrated in the visible bands of the density gradient and produced a colour change due to metabolic activity when transferred to the mycoplasma media.

It has been suggested that mycoplasmas may be present only in early cases of rheumatoid arthritis. This study included several patients whose active disease was recent and who were examined at the earliest stage which is likely to present for hospital treatment. Patients receiving any antimycoplasma drugs were excluded from the study.

The detection of cellular hypersensitivity to $M_{0}$ fermentans in the leucocyte migration inhibition tesp (Williams and others, 1970) has been re-examined b us; using similar mycoplasma antigen preparation we have failed to reproduce their finding of inhibition of cell migration only of rheumatoid leucocytes (Maini, Lemcke, Windsor, and Dumonde, 1973). Although inhibition of leucocytes was observed in a large number of rheumatoid subjects, it was also apparent to a similar degree in some entirely healthy individuals and several hospital patients without joint disease. Our findings cast doubt on the assumption that the cell migration results indicate a causal relationship between rheumatoid arthritis and $M$. fermentans infection.

\section{Summary}

73 fluids from 43 patients with rheumatoid arthritis and five from non-rheumatoid subjects were examined for mycoplasmas. None was isolated from eleven fluids from rheumatoid joints or three fluids from non-rheumatoid joints by direct culture into a variety of suitable media in two independent laboratories. Visible bands obtained by separation of 64 rheumatoid fluids and five non-rheumatoid fluids on sucrose density gradients (after the technique of Williams) similarly yielded no evidence of mycoplasmas on culture.

We should like to thank Mr. T. P. Varley, Wellcome Research Laboratories, for identification of the bacterial isolates, and the Arthritis and Rheumatism Council for general support. 


\section{References}

American Rheumatism Association (1959) Ann. rheum. Dis., 18, 49 (Diagnostic criteria for rheumatoid arthritis, 1958 revision)

BARTHOLOMEW, L. E. (1965) Arthr. and Rheum., 8, 376 (Isolation and characterization of mycoplasmas (PPLO) from patients with rheumatoid arthritis, systemic lupus erythematosus and Reiter's syndrome)

- (1967) Ann. N.Y. Acad. Sci., 143, 522 (Characterisation of mycoplasma strains and antibody studies from patients with rheumatoid arthritis)

Barile, M. F., AND DelGiudice, R. A. (1972) 'Isolations of mycoplasmas' in 'Ciba Foundation Symposium: Pathogenic Mycoplasmas', p. 165. Elzevier, Amsterdam (Isolation of mycoplasmas and their rapid identification by plate epi-immunofluorescence)

- AND KeRn, J. (1971) Proc. Soc. exp. Biol. (N.Y.), 138, 432 (Isolation of Mycoplasma arginini from commercial bovine sera and its implication in contaminated cell cultures)

Chanock, R. M., Hayflick, L., AND Barile, M. F. (1962) Proc. nat. Acad. Sci. (Wash.), 48, 41 (Growth on artificial medium of an agent associated with atypical pneumonia and its identification as a PPLO)

Csonka, G. W., Williams, R. E. O., AND CORSE, J. (1966) Lancet, 1, 1292 (T-strain mycoplasma in non-gonococcal urethritis)

Fraser, K. B., Shirodaria, P. V., Haire, M., ANd Middleton, D. (1971) J. Hyg. (Camb.), 69, 17 (Mycoplasmas in cell cultures from rheumatoid synovial membranes)

Jansson, E., Mäkisara, P., Vainio, K., Vainio, U., Snellman, O., and TuUri, S. (1971) Ann. rheum. Dis., 30, 506 (An 8-year study on Mycoplasma in rheumatoid arthritis)

-, AND WAGER, O. (1967) Ann. N.Y. Acad. Sci., 143, 535 (Mycoplasma in collagen diseases and blood dyscrasia)

LEMCKE, R. M. (1971) Nature (Lond.), 229, 492 (Sizing small organisms)

MAini, R. N., LEMCKE, R. M., WindsoR, G. D., AND DumONDE, D. C. (1973) 'XIII Int. Congr. Rheumatology, 1973', p. 11. Excerpta Medica Int. Congr. Ser. No. 299 (Mycoplasmas and rheumatoid arthritis: studies of cellular hypersensitivity in vitro and attempts at isolation from synovial fluids) MANILOFF, J. (1969) J. Bact., 100, 1402 (Electron microscopy of small cells: Mycoplasma hominis)

Sabin, A. B. (1967) Ann. N.Y. Acad. Sci., 143, 628 (Nature and source of Mycoplasma in various tissue cultures)

SETHI, K. K. (1972) Z. Bakt., I. Abt. Orig. A., 219, 550 (On the incidence of Mycoplasma contamination in cell cultures)

StANBRIDGE, E. (1971) Bact. Rev., 35, 206 (Mycoplasmas and cell cultures)

TAYlor-RoBinson, D. (1973) Ann. rheum. Dis. 32, 389 (Discussion)

Williams, M. H. (1967a) Ph.D. Thesis, Welsh National School of Medicine

- (1967b) 'Recovery of mycoplasma from rheumatoid synovial fluid' in 'Rheumatic Diseases', ed. J. R. R. Duthie and W. R. M. Alexander, p. 172. Pfizer Monograph No. 3, University Press, Edinburgh (1970) 'An immunological response to Mycoplasma fermentations in rheumatoid arthritis' in 'Impaired Cell-mediated Hypersensitivity in Man', ed. J. F. Jennings and D. J. Ward, p. 43. Orthopaedic Hospital, Oswestry, England (An immunological response to Mycoplasma fermentans in rheumatoid arthritis)

- BrostofF, J., AND RortT, I. M. (1970) Lancet, 2, 277 (Possible role of Mycoplasma fermentans in pathogenesis of rheumatoid arthritis) 